\title{
Gwt1 Inhibitor APX001
}

National Cancer Institute

\section{Source}

National Cancer Institute. Gwt1 Inhibitor APX001. NCI Thesaurus. Code C155900.

An orally available small molecule inhibitor of the Gwt1 fungal enzyme with potential antifung al activity. Upon administration APX001, a N-phosphonooxymethyl prodrug, is rapidly and completely metabolized by systemic alkaline phosphatases to its active moiety, APX001A (E1210). The active prodrug targets Gwt1, a highly conserved inositol acylase which catalyzes an essential step in the glycosylphosphatidylinositol (GPI)-anchor biosynthesis pathway. Inhibition of Gwt1 prevents localization of cell wall mannoproteins, which compromises cell wall integ rity, biofilm formation, germ tube formation, and fungal growth. 